\title{
Estudio clínico y determinación de la parasitemia en un grupo de pacientes infectados por Trypanosoma cruzi de la región de Atacama, Chile
}

\author{
Mauricio Carrasco $\mathrm{V}^{1}$, Winston Andrade $\mathrm{L}^{2}$, \\ María Isabel Jercic $L^{2}$, Jorge Fernández $0^{2}$, \\ Claudio Miranda $C^{2}$, Juan Rivera $Q^{1}$, Jorge $G$ onzález $V^{3}$, \\ Luis González $\mathbf{A}^{4}$, Eugenio Ramírez $\mathbf{V}^{2}$. \\ Clinical assessment of subjects
infected with Trypanosoma cruzi
}

Background: Trypanosoma cruzi infection is endemic in Northern/ Central Chile. Aim: To perform a clinical assessment of patients infected with Trypanosoma cruzi. Patients and methods: Two hundred sixty three subjects with a positive serology for Trypanosoma cruzi, were invited by mail to a clinical assessment in a Regional Hospital. In a subsample of these, a polymerase chain reaction for Trypanosoma cruzi, was done. Results: Of all the invited subjects, 183 responded and were assessed at the hospital. Of these, 60 had cardiac affections, 52 had colon problems and 17, esophageal disease. Seventy four were asymptomatic. Of the 64 patients in whom polymerase chain reaction was done, 35 had a positive result. Conclusions: A high percentage of subjects infected with Trypanosoma cruzi, had clinical consequences of the infection. Polymerase chain reaction showed persistency of the parasite in more than half of the infected patients (Rev Méd Chile 2003; 131: 881-6).

(Key Words: Cardiomyopathy, congestive; Polymerase chain reaction; Trypanosoma cruzi)

\begin{abstract}
Recibido el 3 de diciembre, 2002. Aceptado en versión corregida el 10 de junio, 2003. Hospital Regional de Copiapó ${ }^{2}$. Laboratorio Nacional y de Referencia de Parasitología y Unidad de Desarrollo, Instituto de Salud Pública, Santiago ${ }^{2}$. Departamento de Medio Ambiente, Provincia del Huasco, Servicio de Salud Atacama ${ }^{3}$ y Epidemiología Servicio Salud Occidente, Santiago, Chile ${ }^{4}$.
\end{abstract}

L a infección por Trypanosoma cruzi, en Chile, es endémica desde la I a la VI región ${ }^{1,2}$, área en que existe la presencia del Triatoma infestans, el principal transmisor de la enfermedad de Chagas en Chile. También es posible encontrar portadores en áreas no endémicas; por la migración interregional y transmisión transplacentaria de la infec-

Correspondencia a: Dr. Mauricio Carrasco V. Servicio de Medicina Interna, Hospital Regional de Copiapó. Fax: 56 52 212309. E mail: mcarrasco@hospitalcopiapo.cl ción parasitaria. Por lo tanto, la situación respecto al vector, no es la misma que respecto a la portación del parásito, ya que en lugares geográficos donde no hay vector, puede haber enfermedad, tal como sucede en Estados Unidos ${ }^{3,4}$.

En 1984 el Servicio de Salud Atacama (SSA) inició el programa de control del vector, mediante la aplicación sistemática de insecticidas, en las viviendas de las áreas endémicas; seguido de vigilancia entomológica y de educación a la comunidad. Ello ha significado una gran reducción de los focos de 
infestación del vector en las viviendas y, como consecuencia, se ha logrado certificar la intermupción de la transmisión vectorial de la enfermedad. Para evaluar el impacto del programa, en 1996 se efectuó un estudio serológico a 1.555 niños de 0 a 10 años de las áreas endémicas de Atacama, encontrándose que la seropositividad de este grupo etario se redujo de 9,8\% en 1982 a 1\% en 19965,6. En 1999 se efectuó un estudio de 726 niños de 0 a 5 años, no encontrándose ninguno seropositivo por transmisión vectorial y tres casos infectados congénitamente ${ }^{7}$. Resultados similares se han descrito en estudios serológicos realizados con pacientes de otras regiones endémicas chilenas. Como resultado de lo anterior, la Organización Panamericana de la Salud reconoció a Chile en 1999 como un país que ha intermumpido la transmisión vectorial ${ }^{7}$.

Por otra parte, encuestas serológicas en donantes de sangre del Hospital de Copiapó muestran también una disminución de la portación desde 6,5\% en el año 1983 hasta 2,4\% en 1999; respecto de la pregunta: ¿qué pasa con la población expuesta por años al vector y a las otras formas de contagio que aún persisten? Sabemos que estudios chilenos sobre población chagásica, que determinan la condición de afección orgánica de portador asintomático y mortalidad son escasos, antiguos y parciales. En ellos se analizan: presencia o no de cardiopatía, basados principalmente en el electrocardiograma ${ }^{9,10}$ y algunos se preocupan sólo de las complicaciones digestivas proponiendo $28,7 \%$ de megacolon en la población chagásica ${ }^{11}$. Los estudios existentes no brindan información sobre la presencia de estreñimiento sin megacolon o sintomatología esofágica $\mathrm{v} g \mathrm{~g}$, asociación de disfagia y dolor torácico; sin acalasia radiológica, condiciones posibles en el espectro clínico del Chagas ${ }^{12-14}$.

Actualmente es posible determinar la presencia de parasitemia a través del xenodiagnóstico en la fase crónica de la enfermedad ${ }^{15,16}$. Sin embargo, esta metodología parece ser menos sensible que los métodos basados en técnicas de biología molecular, por ejemplo PCR, para determinar parasitemia ${ }^{17,18}$. En este estudio, se planteó como objetivos describir la distribución de los distintos tipos de compromiso orgánico y mortalidad en un grupo chagásico de la región de Atacama y evaluar la presencia de parasitemia en pacientes adultos en fase indeterminada 0 avanzada, mediante reacción de PCR, evaluando su posible relación con la condición clínica de los individuos infectados.

\section{MATERIAL Y MÉTODO}

Pacientes. Desde enero de 1998 a junio de 2001, se pesquisaron 263 individuos con serología positiva para Trypanosoma cruzi. Estos pacientes seropositivos provenían del universo de sujetos a los que habitualmente se les realiza este examen: donantes de sangre o pacientes con sospecha clínica de la enfermedad o que pertenecen a un grupo familiar de un paciente chagásico o por provenir de sectores de alta endemia. Las personas así pesquisadas, fueron citadas por correspondencia, a un policlínico específico, en el Consultorio Adosado de Especialidades, en el Hospital Regional de Copiapó.

Estudio clínico. A cada individuo se le realizó una entrevista médica, un cuestionario sobre síntomas y datos biográficos, más un electrocardiograma (ECG) de reposo. A los pacientes con electrocardiograma normal $\mathrm{y}$ sin síntomas o signos, tales como: estreñimiento, disfagia, dolor torácico, disnea, edema, palpitaciones, 0 mareos, no se les realizó otro procedimiento diagnóstico. A su vez, a los pacientes que presentaban síntomas o alteración en el ECG se les realizaron de acuerdo a ello: enema baritada, tránsito esofágico, endoscopia digestiva alta o baja, radiografía ( $\mathrm{Rx}$ ) de tórax, Holter de ECG o ecocardiografía. Definiéndose así la condición clínica de los pacientes y separándose los siguientes subgrupos:

a. Ausente: persona con serología positiva confirmada para la infección por T cruzi, que no se presentó al control médico. b. Asintomático: Paciente que no refirió sintomatología durante la entrevista, con examen médico y electrocardiograma normal. c. Cardiópata: Trastornos del sistema exitoconductor, arritmias o insuficiencia cardíaca. d. Con afección de colón: estreñimiento con enema baritada normal o megacolon. e. Con afección de esófago: paciente con disfagia y dolor torácico, aunque endoscopia y Rx de esófago fueran normales o con acalasia demostrada por radiología.

Se obtuvo el número de fallecidos del grupo en estudio a través de la búsqueda por RUT, desde base de datos de certificados de defunción del SSA y el seguimiento de los pacientes bajo control.

Exámenes parasitológicos. Los exámenes serológicos fueron realizados en el Banco de Sangre del Hospital de Copiapó y confirmados por IFI en la sección parasitología del Instituto de Salud Pública (ISP). 
Por razones de disponibilidad, sólo a 64 pacientes se les realizó reacción en cadena de polimerasa para T cruzi en el ISP, siguiendo para la extracción del DNA el método de Kirchoff ${ }^{19}$. Este método consiste en mezclar $1,0 \mathrm{ml}$ de sangre periférica del paciente con $4 \mathrm{ml}$ de buffer GEB (Isotiacianato de Guanidina 4 M, EDTA 0,2 M, Tritón X-100 1\%). Se agrega 3 volúmenes de agua desionizada, 0,1 vol de $\mathrm{MgCl} 21 \mathrm{M}, 0,1$ vol de CuSO $4200 \mathrm{mM}, 0,1$ vol de 1,10-Fenantrolina $20 \mathrm{mM}, 0,1$ vol de $\mathrm{H}_{2} \mathrm{O}_{2} 7,5 \%$. La reacción de digestión del DNA se realiza con 0,1 vol de ácido 3-Mercaptopropiónico, incubando por $90 \mathrm{~min}$ a $37^{\circ}$. La digestión se detiene con 0,1 vol de 2,9-Dimetil-1,10-Fenantrolina. Inmediatamente después de la digestión, cada muestra se extrae con 1/ 6 de vol de fenol:cloroformo:isoamílico. Luego, el DNA se precipita con acetato de sodio $3 \mathrm{My}$ etanol frío. El precipitado de DNA es resuspendido en 500 $\mathrm{ml}$ de agua desionizada.

Posteriormente se amplifica una región del gen de la proteína flagelar de $24 \mathrm{kDa}$ que une calcio (TCFCABP) mediante un PCR anillado, de acuerdo a procedimientos previamente descritos ${ }^{20}$. Para el primer PCR se usan los partidores T3 (5'-AGA TGG GTG CTT GTG GGT CGA A-3') y T4 (5'-GGA CAC GGT GTT TAC ATT GGC GA-3'). Para el segundo PCR se emplean los partidores T1 (5'-GAC GGC AAG AAC GCC AAG GAC-3') y T2 (5'-TCA CGC GCT CTC CGG CAC GTT GTC-3'). El producto de la amplificación, un fragmento de 516 pares de bases, es detectado por electroforesis en gel de agarosa al $2 \%$, teñido con bromuro de etidio.

\section{RESULTADOS}

De un total grupal de 263 sujetos seropositivos, pesquisados entre enero de 1998 y junio de 2001, 80 sujetos no acudieron a la citación y 183 fueron evaluados y clasificados clínicamente en diferentes subgrupos, según lo establecido en material y método (Tabla 1). De los 183 pacientes estudiados, 74 (40,4\%) eran asintomáticos (promedio de edad 40,57士10,59 años). Su distribución por sexo comespondió a 46 hombres y 28 mujeres; comespondiendo 49 de ellos a donantes de sangre. De los 109 (59,6\%) sintomáticos sólo 31 fueron pesquisados al donar sangre.

De los 109 pacientes sintomáticos, 60 tenían algún tipo de compromiso cardíaco, cuyas alteraciones se distribuyeron en: 32 sujetos con alteraciones eléctricas, tanto en forma exclusiva como asociada a otro compromiso orgánico, 19 individuos con miocardiopatías (2 asociadas a colopatías y 17 como único compromiso), 9 sujetos con marcapaso definitivo, 7 con compromiso único y 2 asociados a megacolon. El compromiso colónico estuvo dado por 21 casos con megacolon y 31 estreñidos sin megacolon (edades promedios $65,6 \pm 11,26$ y $49,9 \pm 15,5$ años, respectivamente). El compromiso esofágico, la menor de las formas clínicas, se distribuyó en 3 acalasias y en 14 asociación de los síntomas disfagia y dolor torácico sin acalasia radiológica.

Dentro de los enfermos, hubo compromiso de dos órganos diferentes en 20 sujetos: 14 colon/ corazón, 5 colon/esófago y 1 esófago/corazón. En 8 pacientes cardiópatas, se comprobó coexistencia de arritmias, trastornos de conducción o insuficiencia cardíaca. La asociación más frecuente fue megacolon con bloqueo de rama derecha (6 pacientes), megacolon con marcapaso (2 pacientes) y megacolon con insuficiencia cardíaca (1 paciente).

La distribución por edad, se expone en la Tabla 2. Para agrupar por edad en el caso de alteraciones

Tabla 1. D istribución de los pacientes estudiados según sexo y compromiso orgánico

\begin{tabular}{|lcccc|}
\hline $\begin{array}{l}\text { Compromiso } \\
\text { orgánico }\end{array}$ & Femenino & Masculino & \multicolumn{2}{c|}{$\begin{array}{c}\text { Total de } \\
\text { pacientes }\end{array}$} \\
& & & $\mathrm{N}^{\circ}$ & $\%$ \\
\hline Asintomáticos & 28 & 46 & 74 & 40,4 \\
Corazón & 17 & 28 & 45 & 24,5 \\
Colon & 19 & 14 & 33 & 18 \\
Esófago & 6 & 5 & 11 & 6 \\
Dos órganos & 7 & 13 & 20 & 11 \\
Total & 77 & 106 & 183 & 100 \\
\hline
\end{tabular}

Tabla 2. Promedio de edad según la condición clínica en pacientes infectados con $T$ cruzi

\begin{tabular}{|lcc|}
\hline Clasificación & $\begin{array}{c}\text { Promedio } \\
\text { edad (años) }\end{array}$ & $\begin{array}{c}\text { P } \\
\text { V/S asintomático }\end{array}$ \\
\hline Asintomático & $40,6 \pm 10,6$ & \\
Megacolon & $65,6 \pm 15,5$ & $<0,05$ \\
Estreñimiento & $49,9 \pm 15,5$ & $<0,05$ \\
Acalasia & $56,6 \pm 16,9$ & $<0,05$ \\
Disfagia/dolor Tx & $46,1 \pm 9$ & $>0,05$ \\
Insuficiencia cardíaca & $68,4 \pm 12,9$ & $<0,05$ \\
Marcapaso & $54,1 \pm 8,6$ & $<0,05$ \\
Alteraciones ECG & $53,4+19,1$ & $<0,05$ \\
\hline
\end{tabular}


eléctricas, se consideró sólo aquellos casos en que éste era su único compromiso, cuando se presentaba asociada a colopatía, esofagopatía o insuficiencia cardíaca, se consideró la edad del paciente dentro de estos últimos diagnósticos. La significación estadística, se analizó para cada grupo, aplicando la $t$ de student versus el grupo asintomático.

A 64 pacientes, del total de 183, se les realizó reacción en cadena de polimerasa para $\mathrm{T}$ cruzi, obteniéndose un resultado positivo en $35(54,7 \%)$ (Tabla 3). La Tabla 4 muestra la distribución de la parasitemia detectada mediante PCR, separando a los pacientes en asintomáticos y enfermos.

Al analizar la Tabla 4 mediante el ji cuadrado, como una tabla de contingencia de $2 \times 2$, se obtuvo una significación para el PCR; como marcador de mayor probabilidad de afección orgánica, en un individuo portador de T cruzi.

Respecto a las causas de muerte del grupo en estudio desde enero de 1998 a junio de 2001, se clasificó en tres grupos: causa directa por patología chagásica, causa indirecta y no relacionada con la enfermedad (Tabla 5). Las causas directas fueron: dos fallecimientos por insuficiencia cardíaca y uno por arritmia ventricular. Las causas indirectas fueron: un paciente, con trombosis cerebral y megacolon complicado con fecaloma; un paciente con cardiopatía chagásica tratado con amiodarona durante 8 años, que falleció por insuficiencia hepática. Las causas no relacionadas fueron: tres casos de neumonías, tres pacientes con cáncer de vejiga urinaria, dos casos de insuficiencia renal crónica y un paciente con cáncer de origen no precisado.

\section{Discusión}

Este estudio que investiga globalmente el compromiso orgánico en un grupo de pacientes chagásicos
Tabla 3. D istribución de 64 pacientes chagásicos según manifestación clínica y resultados de la Reacción en Cadena de Polimerasas para T cruzi

\begin{tabular}{|lccc|}
\hline $\begin{array}{l}\text { Compromiso } \\
\text { orgánico }\end{array}$ & $\begin{array}{c}\text { PCR } \\
\text { Positivo }\end{array}$ & $\begin{array}{c}\text { PCR } \\
\text { Negativo }\end{array}$ & Total \\
\hline Asintomático & 10 & 16 & 26 \\
Colon & 8 & 4 & 12 \\
Esófago & 3 & 3 & 6 \\
Corazón & 8 & 4 & 12 \\
Dos órganos & 7 & 3 & 10 \\
Total & $35(54,7 \%)$ & $29(45,3 \%)$ & 64 \\
\hline
\end{tabular}

\section{Tabla 4. D istribución de 64 pacientes estudiados según condición clínica y resultado de PCR para T cruzi}

\begin{tabular}{|lccc|}
\hline Resultado PCR & Asintomático & Sintomático & Total \\
\hline Positivo & $10(28,6 \%)$ & $25(71,4 \%)$ & 35 \\
Negativo & $16(55,2 \%)$ & $13(44,8 \%)$ & 29 \\
Total & 26 & 38 & 64 \\
\hline
\end{tabular}

Ji cuadrado estándar: valor ji 4,65 y p=0,03.

señala 59,6\% de sintomáticos, en la población de individuos infectados. Este resultado es mayor de $25 \%$ a $30 \%$, descrito previamente por otros autores ${ }^{11,21,22}$. Si se analiza el grupo con patologías más graves como megacolon, miocardiopatía y acalasia se obtiene $28,4 \%$ de sujetos afectados por alguna de estas complicaciones, lo cual concuerda con estudios anteriores.

Publicaciones previas señalan $28,7 \%$ de megacolon en un grupo de pacientes chagásicos ${ }^{11}$. Nosotros encontramos 40,3\% de megacolon en un grupo de

Tabla 5. D istribución de pacientes chagásicos fallecidos según causa de muerte, edad y sexo

\begin{tabular}{|c|c|c|c|c|c|c|c|}
\hline Categoría & \multicolumn{2}{|c|}{$\begin{array}{l}\text { Causa } \\
\text { directa }\end{array}$} & $\begin{array}{c}\text { Causa } \\
\text { indirecta }\end{array}$ & \multicolumn{2}{|c|}{$\begin{array}{c}\text { No } \\
\text { relacionada }\end{array}$} & \multicolumn{2}{|c|}{ Total } \\
\hline Fallecidos & \multicolumn{2}{|c|}{3} & 2 & \multicolumn{2}{|c|}{9} & \multicolumn{2}{|c|}{14} \\
\hline Sexo & $2 \mathrm{M}$ & $1 \mathrm{~F}$ & $2 \mathrm{M}$ & $5 \mathrm{M}$ & $4 \mathrm{~F}$ & $9 \mathrm{M}$ & $72,8 \pm 10$ \\
\hline Edad (años) & $73 / 86$ & 80 & $81 / 52$ & $81 / 73 / 77 / 70 / 63$ & $80 / 60 / 72 / 70$ & $5 \mathrm{~F}$ & $72,4 \pm 8,3$ \\
\hline
\end{tabular}

M: masculino. F: femenino 
sujetos afectos de la misma enfermedad, pero con estreñimiento. Parece sugerente, desde el punto de vista costo-beneficio, realizar enema baritada, más bien, a los pacientes estreñidos que a todos los portadores de T Cruzi. En coincidencia con otros autores $^{13}$, podemos afirmar que no todos los sujetos chagásicos estreñidos tienen megacolon.

Respecto a los pacientes con cardiopatía, reportes clásicos informan $23,8 \%$ de prevalencia en un grupo chagásico estudiado, sólo con clínica y ECG ${ }^{22}$. En nuestro análisis se estableció que $33,7 \%$ tenían compromiso cardíaco exclusivo o asociado. Quizás, el empleo de mayor número de procedimientos diagnósticos, explicaría las diferencias entre ambos resultados.

La distribución clínica fue 33,7\% de cardiopatías, $28,4 \%$ de colopatías y $9,3 \%$ de esofagopatías, confirmándose el compromiso miocárdico como el más frecuente, tal como se ha descrito previamente ${ }^{10,23}$.

Por otra parte, la edad significativamente mayor de los enfermos respecto de los pacientes asintomáticos, confirma la importancia del tiempo en la expresión clínica de la enfermedad. Por ello es factible proyectar que continuarán apareciendo nuevos enfermos chagásicos en Chile, dentro de la población portadora, a pesar de la emadicación del vector.

La determinación de la parasitemia por PCR mostró resultados positivos en $54,6 \%$ de los casos estudiados (64 pacientes). Estos valores son muy similares a los publicados internacionalmente, cercanos a $59,4 \%{ }^{18}$. Mediante el uso de PCR se detectó parasitemia en $38,4 \%$ y $65,7 \%$ de los pacientes asintomáticos (en fase indeterminada de la enfermedad) y enfermos (en etapas avanzadas de infección), respectivamente. Estos resultados muestran la persistencia del parásito, después de décadas del contagio. Además, nuestros resultados sugieren que la detección de la parasitemia, mediante PCR, podría emplearse como un marcador de mayor probabilidad de afección orgánica, en un individuo portador de T cruzi. Esta situación no ha sido reportada previamente en la

\section{REFERENCIAS}

1. Schenone H, Viliarroel F, Alfaro E. Epidemiología de la Enfermedad de Chagas en Chile, condiciones de la vivienda relacionadas con la presencia de Triatoma Infestans y la proporción de humanos y animales infectados con Trypano- literatura y debería ser confirmada en posteriores investigaciones sobre el tema.

La mortalidad total en el grupo, al cabo de 42 meses de seguimiento, fue 5,3\% (9 hombres y 5 mujeres) con edades promedios de 72,8 y 72,4 años, respectivamente. La mortalidad relacionada directa 0 indirectamente a la Enfermedad de Chagas fue 1,9\%. Finalmente llamó la atención el número de fallecidos por cáncer vesical, situación que se estudiará en trabajos futuros.

El número de sujetos afectados clínicamente por la infección con T cruzi fue elevado. Esta es una población demandante de atención médica, tanto de consulta como de procedimientos diagnósticos (ECG, radiografías, ecocardiografía, Holter de ECG, manometría digestiva, endoscopia digestiva) y terapéuticos (instalación de marcapasos, cirugías digestivas complejas, medicación crónica sintomática según afección de la enfermedad). Todo esto es agravado por la sensación de abandono de los pacientes frente a la falta de tratamiento específico contra la enfermedad, estigmatizada como incurable. Esto a pesar de estudios que muestran un grado de efectividad en la fase crónica, ya sea, con nifurtimox (actualmente discontinuado), benzinidazol (no disponible en Chile) 0 itraconazol ${ }^{24-26}$. Esta precaria situación para los pacientes plantea la necesaria innovación y búsqueda de recursos para el abordaje terapéutico de las complicaciones más graves de esta infección. La creación de policlínicos específicos, permite concentrar estos pacientes, tratar sus complicaciones e intervenir precozmente en la indicación de marcapasos o cirugías digestivas, antes de una situación de emergencia. Por otra parte, la evaluación y empleo de nuevos métodos como el PCR para apoyar el seguimiento clínico de estos pacientes y controlar respuestas a terapias parasiticidas, ya usado en enfermedad de Chagas infantil ${ }^{17}$, puede constituir una herramienta eficaz para mejorar la calidad de vida de los enfermos crónicos infectados con T cruzi.

soma cruzi. Bol Chil Parasitol 1978; 33: 2-7.

2. Rodríguez J, Bertogla J, GordiLo N, Mendoza J, Rojas J, Contreras M et al. Infestación triatomídea domiciliaria e infección por Trypanosoma cruzi en la III Región de Atacama, Chile. Bol Chil Parasit 1982; 37: 29-30.

3. Grant I, Gold J, Wittner M, Tanowitz H, Nathan C, 
MAYER K ET AL. Transfusion associated acute Chagas disease acquired in the United States. Ann Intern Med 1989; 111: 849-51.

4. Herwaldt B, Grijalva M, Newsome A, McGhee C, Powell M, NEMEC D ET AL. Use of polymerase chain reaction to diagnose the fifth reported US case of autochthonous transmission of Trypanosoma cruzi, in Tennesse, 1998. J Infect Dis 2000; 181: 395-9.

5. Schenone $\mathrm{H}$, Contreras $\mathrm{M}$ Del $\mathrm{C}$, Salinas $\mathrm{P}$, Sandoval L, Rojas A, Viliarroel F. Epidemiología de la enfermedad de Chagas en Chile. Frecuencia de la enfermedad de Chagas en Chile. Frecuencia de infección humana por Trypanosoma cruzi por grupos de edad y por regiones. Bol Chil Parasitol 1995; 50: 84-9.

6. González J, Contreras M, Schenone H, Adaos H, CABEZAS R. Enfermedad de Chagas: impacto del programa de control del Triatoma Infestans en la comuna del Alto del Carmen, provincia de Huasco, III región Atacama, Chile. Bol Chil Parasitol 1996; 51: 28-30.

7. Lorca M, García A, Bahamonde M, Fritz A, Tassara R. Certificación serológica de la interrupción de la transmisión vectorial de la enfermedad de Chagas en Chile. Rev Méd Chile 2001; 129: 264-9.

8. Rojas R, Contreras M, Rojas J, Mendoza J, Sandoval L, Amigo C et al. Enfermedad de Chagas en Chile. Sectores urbanos. Prevalencia de la infección chagásica en dadores de sangre del Hospital de Copiapó, III Región, Chile. Bol Chil Parasitol 1983; 38: 26-8.

9. Arribada A, Apt W, Arribada A, Ugarte J, Sandoval J. Cardiopatía chagásica en la provincia de Chañaral. Rev Méd Chile 1980; 108: 1118-24.

10. ARRIBADA A. Cardiopatía chagásica: Historia natural. Enfermedades Parasitarias. Series Clínicas, Sociedad Médica de Santiago 1988, VII: 83-96.

11. Calderón C, Aldana M. Estudio del colon en 150 pacientes con enfermedad de Chagas. Parasitol al día 1985, 9: 79-80.

12. Dantas R, Deghaide N, Donadi E. Esophageal manometric and radiologic findings in asymptomatic subjects with Chagas' disease. J Clin Gastroenterol 1999; 28: 245-8.

13. Santos L, Barcelos I, Mesquita M. Total and segmenteal colonic transit time in constipated patients with Chagas' disease without megaesophagus or megacolon. Braz J Med Biol Res 2000; 33: 43-9.

14. De Oliveira R, Rezende Filho J, Dantas R, Iazigi N. The spectrum of esophageal motor disorders in
Chagas' disease. Am J Gastroenterol 1995; 90: 1119-24.

15. Castro C, Macedo V, Prata A. The behavior of Trypanosoma cruzi parasitemia in chronic chagasics over 13 years. Rev Soc Bras Med Trop 1999; 32: 157-65.

16. Arribada A, Apt W, Aguilera X, Solari A, Arribada M, Sandoval J. Cardiopatía chagásica en la primera región de Chile. Estudio clínico, epidemiológico y parasitológico. Rev Méd Chile 1990; 118: 846-54.

17. Solari A, Contreras M, Lorca M, García A, Salinas P, ORtiz S et al. Utilidad del xenodiagnóstico y PCR en la evaluación de quimioterapia específica para enfermedad de Chagas en niños. Bol Chil Parasitol 1998; 53: 27-30.

18. Junqueira A, Chiari E, Wincker P. Comparison of the polymerase chain reaction two classical parasitological methods for the diagnosis of Chagas disease in an endemic region of northeastern Brazil. Trans R Soc Trop Med Hyg 1996; 90: 129-32.

19. KirchHoff L, Votara J, Ochs D, Moser D. Comparison of PCR and microscopic methods for detecting T cruzi. J Clin Microbiol 1996; 34: 1171-75.

20. Godsel L, Tibbetts R, Olson C, Chandior B, Engman D. Utility of recombinant flagelar calcium-binding protein for serodiagnosis of Trypanosoma cruzi infection. J Clin Microbiol 1995; 33: 2082-5.

21. AcuÑa M, RothHamer F, Moreno R, Barton S, ArRIBAda A, ApT W ET AL. Evidencias genéticas corroboran la hipótesis de Neghme sobre la mayor benignidad de la Tripanosomiasis americana en Chile. Rev Méd Chile 1992; 120: 233-8.

21. Arribada A, Apt W, Ugarte J, Arribada A, Sandoval J. Epidemiología de la cardiopatía chagásica en Chile. Rev Méd Chile 1981; 109: 1199-207.

23. AтıAs A. Enfermedad de Chagas digestiva en Chile, experiencia de 20 años. Bol Hosp S J de Dios 1980; 27: 251-7.

24. OPS/HCP/HCT/140/99. Tratamiento etiológico de la Enfermedad de Chagas. Fundación Oswaldo Cruz, Río de Janeiro, Brasil 23-25 abril, 1998.

25. FerReira H. Tratamento da forma indeterminada da doença de Chagas com nifurtimox e benznidazol. Rev Soc Bras Med Trop 1990; 23: 209.

26. Apt W, Aguilera X, Arribada A, Pérez C, Miranda C, Sánchez G et al. Treatment of chronic Chagas' disease with itraconazole and allopurinol. Am J Trop Med Hyg 1998; 59: 133-8. 